\title{
Studies on the Coagulation of Chicken Blood
}

\author{
V. Differentiation and Assay of Labile Factors, Adsorbable by \\ Barium Carbonate
}

\author{
$\emptyset$ Y V I N D S $\varnothing$ R Y E* and INGER KRUSE
}

\begin{abstract}
Department of Biochemistry and Nutrition, Polytechnic Institute, Copenhagen, Denmark
\end{abstract}
\begin{abstract}
Studies on the effect of adsorbents on the labile factor activity of fresh oxalated plasmas have revealed that this activity is of a complex nature. Only a part of the labile factor activity can be adsorbed by barium or strontium carbonates, and it is shown that each of these two compounds adsorbs two different labile factors - $\varphi$ (psi)factor and $\sigma$ (sigma)-factor - which can be adsorbed separately by other selective adsorbents. The minimum amount of adsorbent required for complete adsorption of each labile factor seems to be proportional to the concentration of the factor. $\psi$-Factor and $\sigma$-factor also contribute to the labile factor activity measured when Russell's viper venom, with or without cephalin, is substituted for thromboplastin.
\end{abstract}

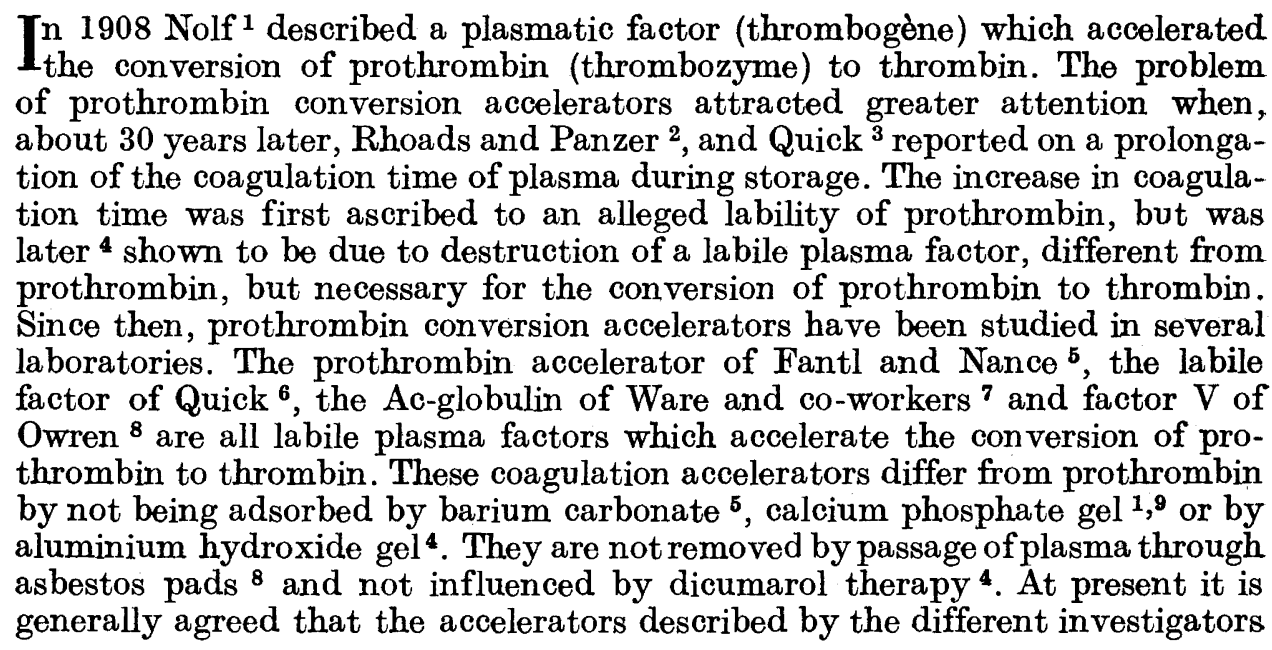

* Fellow of the Royal Norwegian Council for Scientific and Industrial Research.

Acta Chem. Scand. 16 (1962) No. 5 
are identical, and that the terms: prothrombin accelerator, labile factor, Acglobulin, factor $\mathrm{V}$, and proaccelerin are synonyms for the same coagulation factor.

In this laboratory we have been concerned with the problems of differentiation and assay of coagulation factors in chicken blood in connection with planned studies on the influence of dietary factors on the formation of coagulation factors. The interest in the labile factor activity of fresh chicken plasma was aroused by the experience that the thromboplastin accelerated coagulation time of oxalated chicken plasma increased at least fourfold on storage at $5-6^{\circ} \mathrm{C}$ for $4-5$ days. This gave easy access to substrate plasmas for studies of the coagulation factors which are reduced below optimal levels during shorttime storage.

In connection with the studies on the $x$-, $\delta$-, and $\varphi$-factors of normal, vitamin K-deficient and of dicumarol (or coumachlor) plasmas ${ }^{10,12}$, the plasmas were also investigated with regard to their labile factor activity, defined as the activity of plasma factors which accelerate the coagulation of stored, oxalated normal plasma. It was found that complete adsorption of the $\varkappa$-, $\delta$-, and $\varphi$-factors from oxalated plasma by strontium carbonate or barium carbonate also resulted in a limited reduction of the labile factor activity. A further reduction of the labile factor activity could not be obtained by increasing the amounts of adsorbent, nor by renewed treatment with the adsorbent. These experiments indicated that the labile factor activity of fresh oxalated chicken plasma must be due both to strontium carbonate adsorbable and to strontium carbonate non-adsorbable factors, and thus cannot be attributed to a single coagulation factor. In the present and forthcoming papers it will be shown that the labile factor activity of fresh oxalated chicken plasma can be regarded as the combined activity of a number of labile coagulation factors, the differences between which are revealed by adsorption experiments, using crystalline adsorbents. The present study deals with adsorption of the labile factor activity which is adsorbed by barium carbonate or strontium carbonate, simultaneously with the adsorption of the $*$-, $\delta$-, and $\varphi$-factors.

\section{MATERIALS AND METHODS}

The materials and methods for coagulation time determinations were described previously ${ }^{10}$. The details of a general adsorption technique were also presented ${ }^{10}$. The adsorbents used in this work were those used in the studies on the adsorption of the $x$-, $\delta$-, and $\varphi$-factors ${ }^{11}$.

Stored plasma. Oxalated plasma from normal chickens ${ }^{10}$ was stored in cotton plugged or rubber stoppered tubes at $5-6^{\circ} \mathrm{C}$. After $4-5$ days the thromboplastin coagulation time had increased at least fourfold. Such plasmas were used as substrates for evaluation of the labile factor activities of fresh plasmas.

Coagulation time determination. In addition to the thromboplastin coagulation time (tpl.-time) and the Russell's viper venom (RVV)-cephalin time tests described 10, two modifications of the latter were occasionally used: RVV-buffer times were determined by substituting buffer for cephalin, and RVV-times by leaving out the addition of cephalin or buffer. 


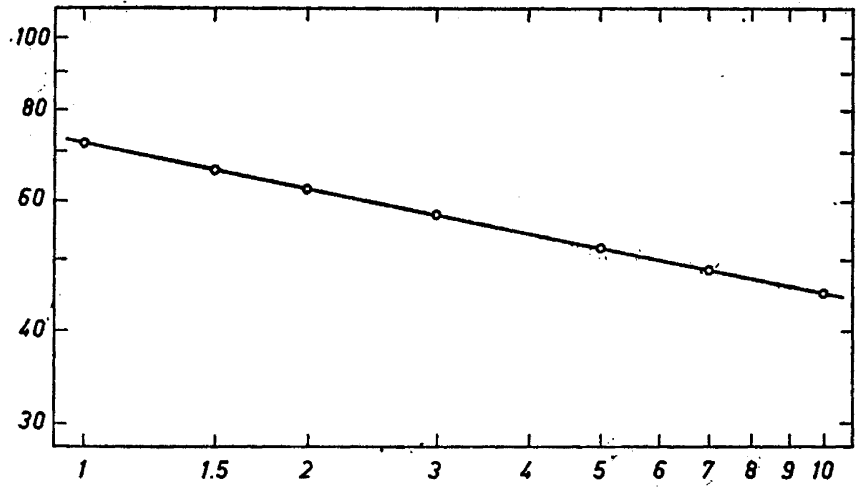

Fig. 1. Dilution curve for labile factor activity. Ordinate: coagulation time in min/100. Abscissa: concentration of fresh plasma in $\%(v / v)$

Determination of the labile factor activity.

Test system: $0.2 \mathrm{ml}$ stored oxalated plasma

$0.2 \mathrm{ml}$ dilution of test sample (in buffer)

$0.2 \mathrm{ml}$ thromboplastin solution

$0.2 \mathrm{ml} \mathrm{CaCl} \mathrm{s}_{2}$-solution ( $30 \mathrm{mM}$ ).

The coagulation time of this test system varies with the concentration of the coagulation factors which are reduced below optimal levels in the stored plasma. Dilutions of the test sample were made with veronal buffer ${ }^{10}$. A test system with cephalin replacing thromboplastin and RVV.CaCl, ${ }_{2}{ }^{10}$ replacing $\mathrm{CaCl}_{2}$, and a similar system system without added cephalin, were used to reveal possible differences between the labile factor activity measured by thromboplastin and the similar activities measured by RVV-cephalin or RVV alone, respectively.

\section{EXPERIMENTS AND RESULTS}

Determination of labile factor activity. A plot of the coagulation time of stored plasma as a function of the concentration of added fresh plasma gives a straight line on double logarithmic paper for the range $1-10 \%(v / v)$ (Fig. 1). Plasmas with very high or very low activities may show deviations from the straight line at higher or lower concentrations, respectively. When RVVcephalin or RVV was substituted for thromboplastin, similar dilution curves were obtained, shifted to shorter or longer coagulation times, respectively.

Different fresh plasmas gave identical or parallel lines when tested with the same stored plasma (Fig. 2), showing that the labile factor activities of different plasmas may be different. Curves obtained with one fresh plasma and different stored plasmas were not necessarily identical or of the same slope, as shown in Fig. 3.

The position and slope of the dilution curves may thus vary from one experiment to another, depending on the sensitivity of the substrate and the activity of the fresh plasma. As the potency of the assay accelerator solution (thromboplastin, RVV-cephalin, or RVV) may also be subject to slight variations, a new dilution curve should be prepared in each experiment. A com- 


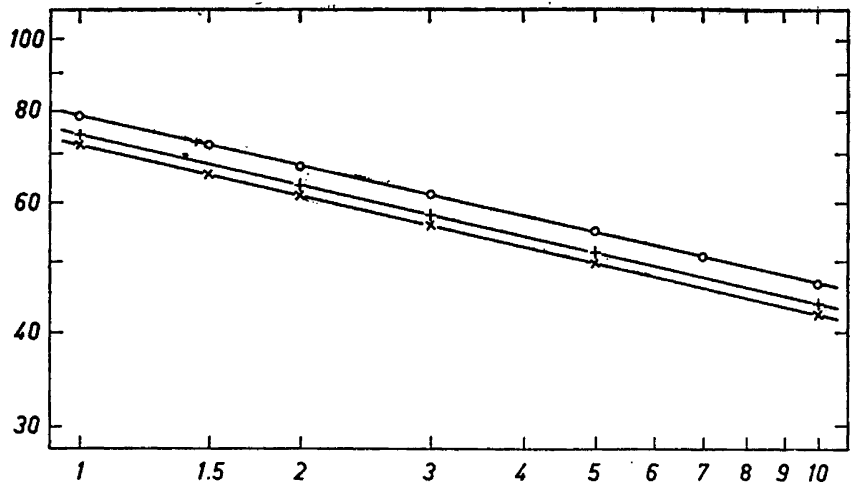

Fig. 2. Dilution curves for three plasmas tested with the same stored plasma. Ordinate: coagulation time in min/100. Abscissa: concentration of fresh plasma in $\%(v / v)$. O: plasma $\mathrm{A} ; \mathrm{t}$ : plasma $\mathrm{B}$; $\times$ : plasma $\mathrm{C}$.

parison of the labile factor activities of different plasmas must therefore be done by simultaneous determination of the activitios of the plasmas, employing the same sample of stored plasma and the same solution of assay accelerator. Thus, only the relative labile factor activities of different plasmas can be determined by this technique. The results of different experiments could not be expected to be directly comparable without rigorous control of the potency of the accelerator solution and of the sensitivity of the stored plasma. A standard dilution of $5 \%$ was chosen for determination of the labile factor activities of plasmas relative to the activity of a plasma used for preparation of the dilution curve. The recorded coagulation times were reproducible with no more difference than $0.1 \mathrm{sec}$, corresponding to differences in labile factor activity of less than $1 \%$.

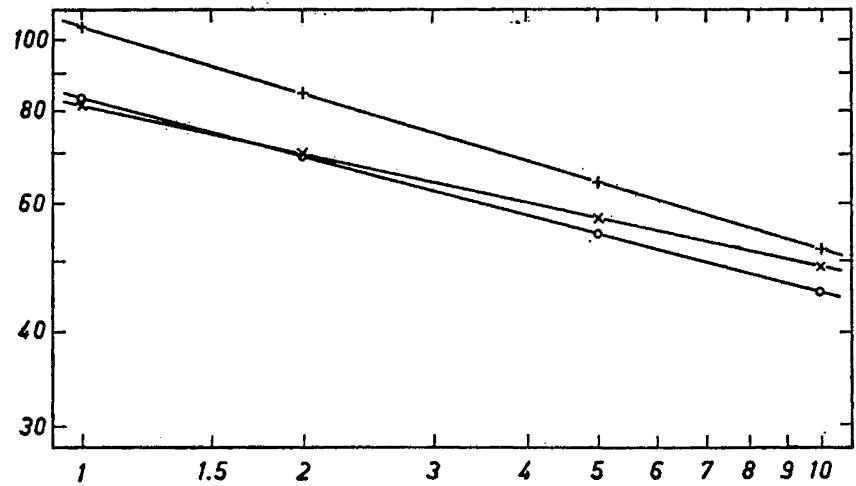

Fig. 3. Dilution curves for a plasma tested with three different stored plasmas. Ordinate: coagulation time in min/100. Abscissa: concentration of fresh plasma in \% (v/v). O: stored plasma A; +: stored plasma B; $\times$ : stored plasma $\mathbf{C}$. 


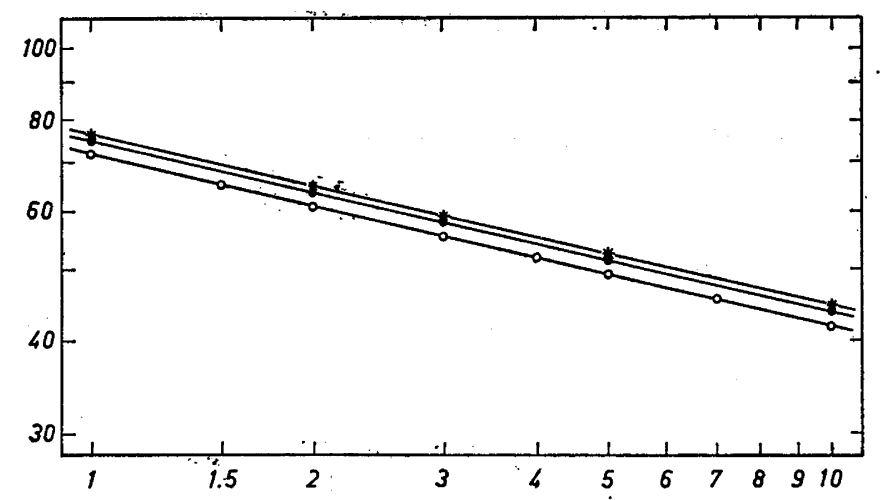

Fig. 4. Dilution curves for untreated and adsorbed plasmas. Ordinate: coagulation time in min/100. Abscissa: concentration of fresh (adsorbed) plasma in $\%(v / v)$.

O: untreated plasma.

- plasma adsorbed with $10 \mathrm{mg} / \mathrm{ml}$ barium carbonate.

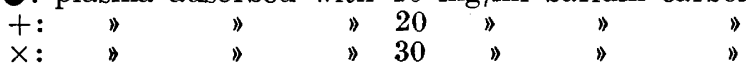

Adsorption of the labile factor activity. Oxalated plasmas were used for adsorption studies. During a preliminary testing of the adsorbents it was ensured that treatment of the plasma with an adsorbent caused no or only a minimal change in $\mathrm{pH}$. It was also controlled that the adsorbed plasma did not contain significant amounts of inhibitors derived from the adsorbent. This was done by comparing the labile factor activity of the adsorbed plasma to that of the untreated plasma at different dilutions. Absence of inhibitors was indicated by corresponding results. The dilution curves for the untreated and the adsorbed plasma were then parallel as shown for untreated and barium carbonate adsorbed plasmas in Fig. 4, and the activity of the adsorbed plasma could be expressed in terms of the activity of the original plasma.

During the last ten years about one hundred and fifty crystalline inorganic compounds have been tested for adsorption of labile factor activity. More than one hundred of the compounds satisfied the above requirements. Their effects on plasma could thus not be attributed to release of inhibitors or $\mathrm{pH}$ changes, but were ascribed to adsorption of labile coagulation factors. The adsorbents were further tested for selectivity, i.e. ability to adsorb only a part of the labile factor activity of the plasma with increasing amounts of adsorbent. The present study is confined to the compounds which adsorbed the same or a smaller part of the labile factor activity which could be adsorbed by barium carbonate or strontium carbonate. The results of a preliminary testing are summarized in Table 1. Five of the fifteen adsorbents tested did not reduce the labile factor activity of oxalated plasma. The remaining ten adsorbents were able to adsorb only a part of the total activity and could be classified as selective adsorbents.

During this and subsequent work it was noticed that the ratio of adsorbable to total activity could vary widely in different experiments with the same

Acta Chem. Scand. 16 (1962) No. 5 
Table 1. Adsorption of labile factor activity.

\begin{tabular}{|c|c|c|c|}
\hline Plasma No. & \multicolumn{2}{|c|}{ Adsorbent $\mathrm{mg} / \mathrm{ml}$} & $\begin{array}{l}\text { Labile factor } \\
\text { activity in } \% \text { of } \\
\text { untreated plasma }\end{array}$ \\
\hline 4128 & $\mathrm{CaF}_{2}$ & 20 & 100 \\
\hline 4128 & $\mathrm{PbCrO}$ & 20 & 100 \\
\hline 4128 & $\mathrm{BiF}_{3}$ & 20 & $\begin{array}{l}100 \\
100\end{array}$ \\
\hline 4103 & $\mathrm{CdCO}_{3}$ & 20 & $\begin{array}{l}100 \\
100\end{array}$ \\
\hline 4102 & $\mathrm{Mg}_{3}\left(\mathrm{AsO}_{4}\right)_{2}$ & 20 & $\begin{array}{l}100 \\
100\end{array}$ \\
\hline 4103 & $\mathrm{CaC}_{2} \mathrm{O}_{4}$ & $\begin{array}{r}80 \\
5\end{array}$ & $\begin{array}{r}100 \\
92\end{array}$ \\
\hline 3511 & $\mathrm{SrC}_{2} \mathrm{O}_{4}$ & 50 & $\begin{array}{l}92 \\
90\end{array}$ \\
\hline 3522 & $\mathrm{BaC}_{2} \mathrm{O}_{4}$ & $\begin{array}{r}50 \\
5\end{array}$ & $\begin{array}{l}90 \\
92\end{array}$ \\
\hline 4102 & $\mathrm{CaMoO}$ & $\begin{array}{l}40 \\
20\end{array}$ & $\begin{array}{l}92 \\
93\end{array}$ \\
\hline 4102 & $\mathrm{BaCrO}_{4}$ & 20 & $\begin{array}{l}80 \\
89 \\
89\end{array}$ \\
\hline 4103 & $\mathrm{CaCO}_{3}$ & 20 & 92 \\
\hline $\begin{array}{l}4118 \\
3508\end{array}$ & $\begin{array}{l}\mathrm{SrCO}_{3} \\
\mathrm{SrCO}_{3}\end{array}$ & $\begin{array}{l}25 \\
20 \\
40\end{array}$ & $\begin{array}{l}87 \\
78 \\
78\end{array}$ \\
\hline 3516 & $\mathrm{BaCO}_{3}$ & $\begin{array}{l}20 \\
80\end{array}$ & $\begin{array}{l}73 \\
73\end{array}$ \\
\hline 4118 & $\mathrm{PbS}$ & 20 & $\begin{array}{l}87 \\
87\end{array}$ \\
\hline 4103 & $\mathrm{MnCO}_{3}$ & $\begin{array}{l}50 \\
80\end{array}$ & $\begin{array}{l}83 \\
83\end{array}$ \\
\hline
\end{tabular}

adsorbent. Such differences are apparent in the recorded experiments with strontium carbonate as adsorbent, where the ratio in two experiments was 0.87 and 0.78 , respectively. Such differences may arise from differences in the sensitivity of the test substrates to adsorbable and non-adsorbable factors, but also from differences between individual fresh plasmas in the concentrations of adsorbable and non-adsorbable factors.

The adsorption of labile factor activity by the selective adsorbents was studied in greater details by determination of the labile factor activity of a series of plasma aliquots adsorbed with graded amounts of adsorbent. Some of the typical adsorption curves obtained are shown in Figs. $5 \mathrm{~A}-\mathrm{H}$. The labile factor activity was adsorbed proportionally to the amount of adsorbent added, until the curve abruptly became horizontal at a certain concentration of adsorbent, indicating that further adsorption of labile factor activity could not be accomplished by increasing the amounts of adsorbent. It was also 

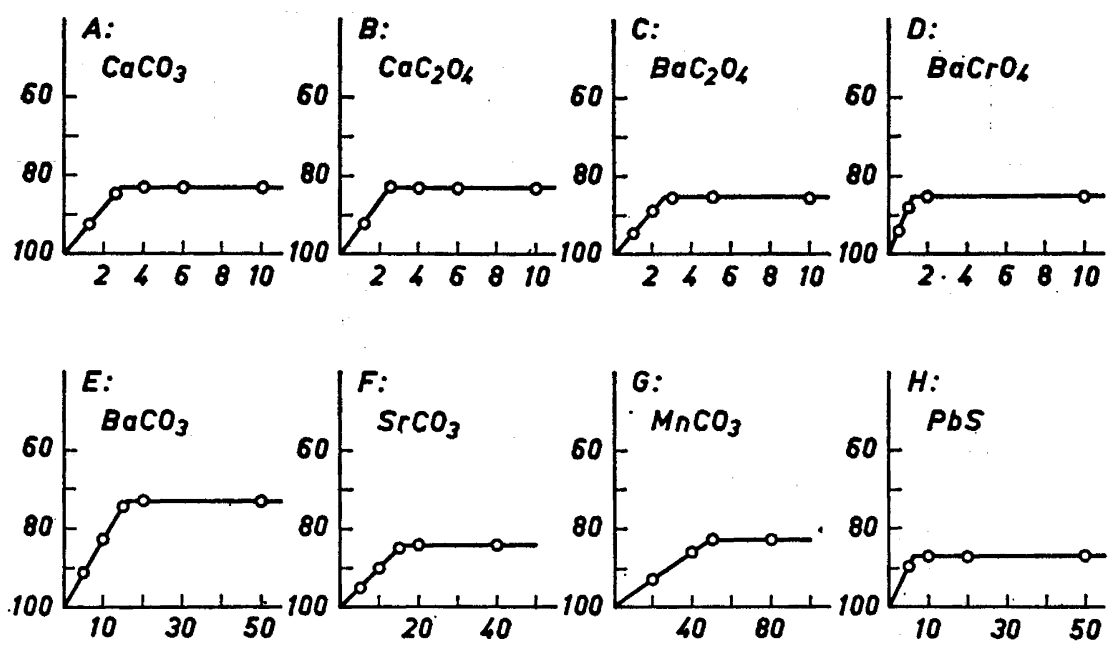

Fig. 5. Adsorption of labile factor activity by selective adsorbents. Ordinates: labile factor activity in \% of original plasma. Abscissæ: adsorbent in $\mathrm{mg} / \mathrm{ml}$.

A: calcium carbonate, B; calcium oxalate, C: barium oxalate, D: barium chromate, E: barium carbonate, $F$ : strontium carbonate, G: manganese carbonate, H: lead sulfide.

found that renewed treatment with the same adsorbent caused no further reduction of the labile factor activity. Such adsorption curves were obtained with all the selective adsorbents.

The partial adsorbability of the labile factor activity by these adsorbents indicates that the adsorbable and the non-adsorbable activities are not due to the same (groups of) labile coagulation factors. The labile factor activity of fresh oxalated chicken plasma should be regarded, therefore, as the combined activity of separate coagulation factors with characteristic differences in adsorbability.

In Table 2 is shown that the labile factor activity of plasma is reduced by column adsorption to the same extent as by batch adsorption with the same adsorbent except in the first few drops of effluent plasma. The presence or absence of $x$-factor, $\delta$-factor, $\phi$-factors, and other factors requiring large amounts of adsorbent for complete adsorption, is thus of no consequence for the labile factor activity of the fresh plasma. The plasma concentrations of these factors cannot be reduced to any greater extent during short time storage at $6^{\circ} \mathrm{C}$, at least not below optimal levels.

Matching experiments. A comparison of the effects of different adsorbents was carried out in a series of matching experiments: One portion of a plasma was preadsorbed with a certain quantity of an adsorbent. It was generally ensured that the quantity of adsorbent used for preadsorption was sufficient for maximal adsorption of labile factor activity. Another portion of the same plasma was not pretreated. Curves for adsorption of the labile factor activities of the untreated and of the preadsorbed plasmas by another adsorbent were

Acta Chem. Scand. 16 (1962) No. 5 
Table 2. Column adsorption versus batch adsorption.

\begin{tabular}{|c|c|c|c|}
\hline Plasma No. & Adsorption treatment & $\begin{array}{l}\text { Tpl.-time } \\
\text { in } \min / 100\end{array}$ & $\begin{array}{l}\text { Labile factor } \\
\text { activity in \% }\end{array}$ \\
\hline 3517 & $\begin{array}{l}\text { Untreated } \\
\text { Column of }\left\{\begin{array}{l}0-1 \mathrm{ml} \text { effluent } \\
1-2 \\
2-3 \\
2-3 \mathrm{grC}_{2} \mathrm{O}_{4} \\
5-6\end{array}\right. \\
\mathrm{SrC}_{2} \mathrm{O}_{4}, 5 \mathrm{mg} / \mathrm{ml} \\
\mathrm{BaC}_{2} \mathrm{O}_{4}, 10\end{array}$ & $\begin{array}{l}28 \\
\infty \\
\infty \\
78 \\
43 \\
\mathbf{3 6} \\
29 \\
\mathbf{2 9}\end{array}$ & $\begin{array}{r}100 \\
87 \\
94 \\
94 \\
94 \\
94 \\
94 \\
94 \\
\end{array}$ \\
\hline 3511 & 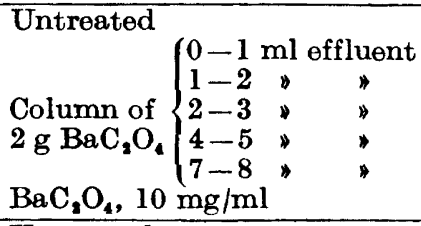 & $\begin{array}{l}26 \\
\infty \\
\infty \\
\infty \\
\infty \\
\infty \\
27\end{array}$ & $\begin{array}{r}100 \\
61 \\
94 \\
94 \\
94 \\
94 \\
94\end{array}$ \\
\hline 4120 & 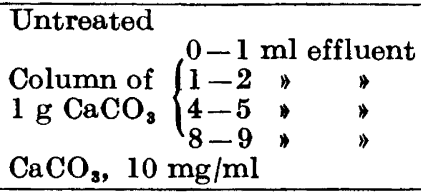 & $\begin{array}{l}22 \\
31 \\
23 \\
23 \\
23 \\
23 \\
\end{array}$ & $\begin{array}{r}100 \\
93 \\
93 \\
93 \\
93 \\
93 \\
\end{array}$ \\
\hline 3510 & 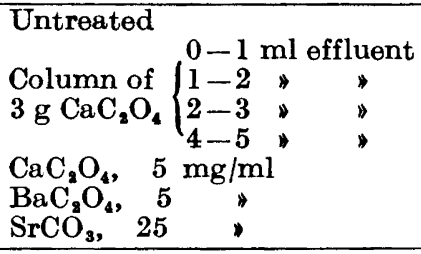 & $\begin{array}{l}23 \\
\infty \\
\infty \\
\infty \\
\infty \\
24 \\
23.8 \\
\infty \\
\end{array}$ & $\begin{array}{r}100 \\
82 \\
90 \\
90 \\
90 \\
90 \\
94 \\
84 \\
\end{array}$ \\
\hline
\end{tabular}

then determined simultaneously. The results of such experiments are presented in Figs. 6 and $7(\mathrm{~A}-\mathrm{H})$.

From Fig. $6 \mathrm{~A}$ it is apparent that the labile factor activity which can be adsorbed by barium oxalate is not affected by preadsorption of the plasma on a calcium oxalate column. The same amount of adsorbent is required for maximal adsorption of the labile factor activity of the untreated and the preadsorbed plasma, and the barium oxalate adsorbable activity is the same in both plasmas, viz. $12 \%$ of the original activity. The experiment shows that the labile factors adsorbed by barium and calcium oxalates are different and that the activity of the factor adsorbed by barium oxalate is independent of the activity of the factor adsorbed by calcium oxalate.

Similarly, the labile factor which can be adsorbed by calcium oxalate or calcium carbonate was unaffected by preadsorption of the plasma on a barium oxalate column (Figs. 6B and 6C). The labile factor activity adsorbed by calcium carbonate was also unrelated to the activity removed by preadsorption with barium chromate $(20 \mathrm{mg} / \mathrm{ml})$ (Fig. 6D).

Acta Chem. Scand. 16 (1962) No. 5 

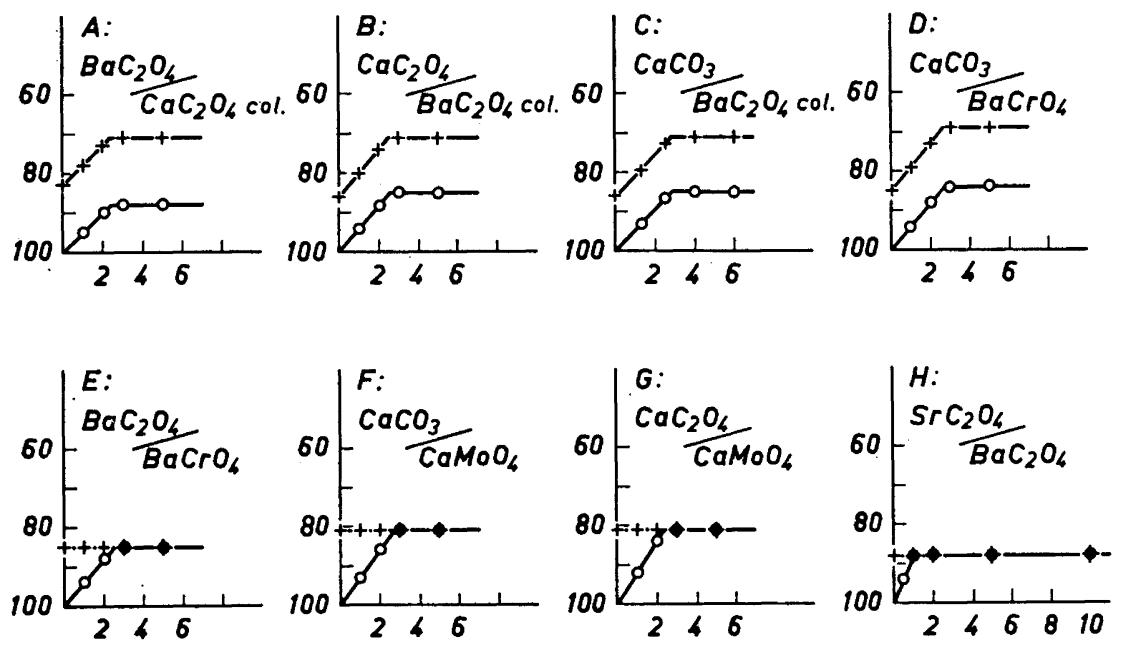

Figs. 6. Adsorption of labile factor activity from untreated and preadsorbed plasmas. Ordinates: labile factor activity in \% of original plasma. Abscissæ: adsorbent in $\mathrm{mg} / \mathrm{ml}$. O: untreated plasma. + : preadsorbed plasma.

A: barium oxalate adsorption of untreated and calcium oxalate column (4 g) preadsorbed plasma (first $\mathrm{ml}$ discarded, the next five $\mathrm{ml}$ collected). B: calcium oxalate adsorption of untreated and barium oxalate column $(3 \mathrm{~g})$ preadsorbed plasma (first ml discarded, the next five $\mathrm{ml}$ collected). C: calcium carbonate adsorption of untreated and barium oxalate column $(3 \mathrm{~g})$ preadsorbed plasma (first $\mathrm{ml}$ discarded, the next five $\mathrm{ml}$ collected). D: calcium carbonate adsorption of untreated and barium chromate $(20 \mathrm{mg} / \mathrm{ml})$ preadsorbed plasma. E: barium oxalate adsorption of untreated and barium chromate $(20 \mathrm{mg} / \mathrm{ml})$ preadsorbed plasma. F: calcium carbonate adsorption of untreated and calcium molybdate (10 $\mathrm{mg} / \mathrm{ml}$ ) preadsorbed plasma. G: calcium oxalate adsorption of untreated and calcium molybdate $(10 \mathrm{mg} / \mathrm{ml})$ preadsorbed plasma. $\mathrm{H}$ : strontium oxalate adsorption of untreated and barium oxalate $(5 \mathrm{mg} / \mathrm{ml})$ preadsorbed plasma.

Barium oxalate adsorption of untreated plasma reduced the labile factor activity to the same level as obtained with barium chromate, but caused no further reduction of a barium chromate preadsorbed plasma (Fig. 6E). The labile factor adsorbed by these two adsorbents was therefore considered to be identical.

Similar experiments with calcium carbonate, calcium oxalate, and calcium molybdate (Figs. 6F and 6G) established the identity of the labile factor adsorbed by these three adsorbents, and a comparison of the activities adsorbed by strontium and barium oxalates (Figs. $6 \mathrm{H}$ and $7 \mathrm{~A}$ ) proved that the latter two adsorbents adsorbed the same labile coagulation factor.

The term $\sigma$ (sigma)-factor has been chosen for the labile coagulation factor which can be adsorbed from oxalated plasma by barium oxalate, barium chromate or strontium oxalate. The term $\psi(p s i)$-factor was adopted for the labile coagulation factor which can be adsorbed from oxalated plasma by calcium carbonate, calcium oxalate or calcium molybdate.

The labile factor activities adsorbed by strontium carbonate, barium carbonate, lead sulfide, and manganese carbonate were compared in the experi-

Acta Chem. Scand. 16 (1962) No. 5 

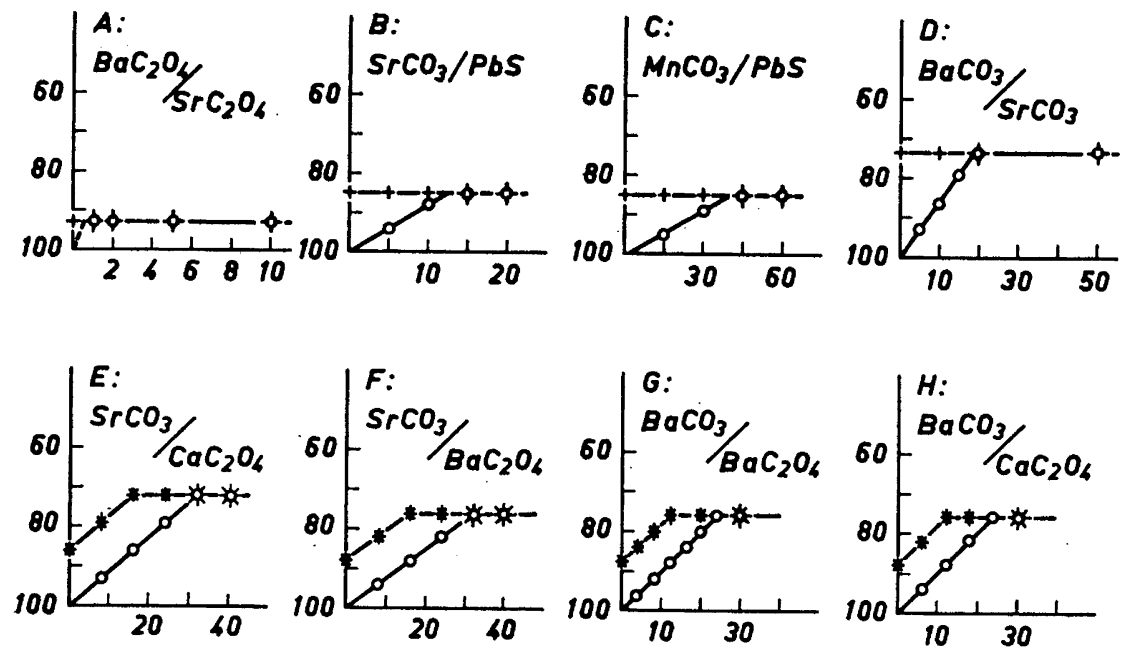

Fig. 7. Adsorption of labile factor activity from untreated and preadsorbed plasmas. Ordinates: labile factor activity in \% of original plasma. Abscissæ: adsorbent in $\mathrm{mg} / \mathrm{ml}$. O: untreated plasma. + and $\times$ : preadsorbed plasmas.

A: barium oxalate adsorption of untreated and strontium oxalate $(5 \mathrm{mg} / \mathrm{ml})$ preadsorbed plasma. B: strontium carbonate adsorption of untreated and lead sulfide $(20 \mathrm{mg} / \mathrm{ml})$ preadsorbed plasma. C: manganese carbonate adsorption of untreated and lead sulfide (20 $\mathrm{mg} / \mathrm{ml}$ ) preadsorbed plasma. D: barium carbonate adsorption of untreated and strontium carbonate $(25 \mathrm{mg} / \mathrm{ml})$ preadsorbed plasma. E: strontium carbonate adsorption of untreated plasma and plasma preadsorbed with $5(+)$ and $200(\times) \mathrm{mg} / \mathrm{ml}$ calcium oxalate. F: strontium carbonate adsorption of untreated plasma and plasma preadsorbed with $3(+)$ and $60(x) \mathrm{mg} / \mathrm{ml}$ barium oxalate. G: barium carbonate adsorption of untreated plasma and plasma preadsorbed with $3(+)$ and $60(x) \mathrm{mg} / \mathrm{ml}$ barium oxalate. H: barium carbonate adsorption of untreated plasma and plasma preadsorbed with 5 $(+)$ and $200(\times) \mathrm{mg} / \mathrm{ml}$ calcium oxalate.

ments of Figs. 7B-D. It was concluded that the four adsorbents adsorbed the same part of the labile factor activity.

In Figs. $7 \mathrm{E}-\mathrm{H}$ the labile factor activities adsorbed by strontium or barium carbonates were compared to the activity adsorbed by calcium or barium oxalates. It will be seen that preadsorption by calcium or barium oxalates removes only a part of the labile factor activity which can be adsorbed by barium or strontium carbonates. The amounts of adsorbent required for maximal adsorption of the labile factor activity of the preadsorbed plasma was reduced proportionally. This means that $\psi$-factor and $\sigma$-factor are adsorbed simultaneously by strontium carbonate and by barium carbonate, and the two factors are adsorbed competitively. The curves for plasmas preadsorbed with 5 and $200 \mathrm{mg} / \mathrm{ml}$ calcium oxalate were identical as were the curves for plasmas preadsorbed with 3 and $60 \mathrm{mg} / \mathrm{ml}$ barium oxalate. It is concluded that the competitive adsorption of $\psi$-factor and $\sigma$-factor by strontium and barium carbonates in independent of the concurrent adsorption of $x$-, $\delta$-, and $\varphi$-factors. 
Table 3. Labile factors measured by RVV-cephalin or RVV.

\begin{tabular}{|c|c|c|c|c|}
\hline \multirow[t]{2}{*}{ Adsorbent } & \multirow[t]{2}{*}{$\mathrm{mg} / \mathrm{ml}$} & \multicolumn{3}{|c|}{ Labile factor activity in \% } \\
\hline & & Tpl. & RVV-ceph. & RVV \\
\hline $\begin{array}{l}\text { Untreated } \\
\mathrm{CaCO}_{3} \\
\mathrm{SrCO}_{3}\end{array}$ & $\begin{array}{r}\mathbf{1} \\
\mathbf{2} \\
\mathbf{3} \\
\mathbf{5} \\
\mathbf{1} \\
\mathbf{2} \\
\mathbf{3} \\
\mathbf{5} \\
\mathbf{2 5} \\
\end{array}$ & $\begin{array}{l}100 \\
95 \\
90 \\
86.5 \\
\mathbf{8 6 . 5} \\
94 \\
88 \\
85 \\
85 \\
71.5 \\
\end{array}$ & $\begin{array}{c}100 \\
\mathbf{9 4 . 5} \\
\mathbf{8 9} \\
\mathbf{8 5} \\
\mathbf{8 5} \\
\mathbf{9 4} \\
\mathbf{8 8} \\
\mathbf{8 5} \\
\mathbf{8 5} \\
\mathbf{7 0} \\
\end{array}$ & $\begin{array}{l}\mathbf{1 0 0} \\
\mathbf{9 6 . 5} \\
\mathbf{9 3} \\
\mathbf{9 0 . 5} \\
\mathbf{9 0 . 5} \\
\mathbf{9 6} \\
\mathbf{9 2} \\
90 \\
90 \\
\mathbf{8 0 . 5} \\
\end{array}$ \\
\hline \multicolumn{2}{|l|}{ Plasma No. } & 4679 & 5050 & 5067 \\
\hline
\end{tabular}

The labile factor activity measured by $R V V$-cephalin or $R V V$. In the above experiments thromboplastin was used as assay accelerator. Additional experiments with RVV-cephalin or RVV replacing thromboplastin are summarized in Table 3. It is apparent that both calcium carbonate and barium oxalate reduce the labile factor activity measured by RVV-cephalin or RVV alone. The same amounts of the two adsorbents were required for maximal adsorption of activity in the three test systems, viz. $2.7 \mathrm{mg} / \mathrm{ml}$ calcium carbonate and $2.5 \mathrm{mg} / \mathrm{ml}$ barium oxalate. The maximal effect of stron tium carbonate equalled the combined effects of calcium carbonate and barium oxalate. The results indicate that $\psi$-factor and $\sigma$-factor also contribute to the labile factor activity measured with RVV-cephalin or RVV as assay accelerators.

Table 4. Plasma coagulation time and $\varphi$ - and $\sigma$-factor concentration. Plasma No. 315.

\begin{tabular}{|c|c|c|c|}
\hline \multicolumn{2}{|c|}{ Plasma treatment } & $\begin{array}{l}\text { Tpl.-time } \\
\text { in } \min / 100\end{array}$ & $\begin{array}{l}\text { Labile factor } \\
\text { activity in } \%\end{array}$ \\
\hline \multicolumn{2}{|c|}{ Untreated } & 25 & 100 \\
\hline 1 & $\mathrm{mg} / \mathrm{ml} \mathrm{CaCO}_{3}$ & 25 & 95.5 \\
\hline 2 & $\|$ & 25 & 91 \\
\hline 2.4 & 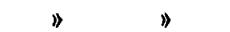 & 25 & - \\
\hline 2.5 & 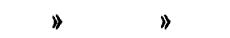 & 25.1 & 88.5 \\
\hline 2.6 & 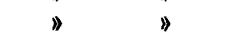 & 25.4 & - \\
\hline 2.8 & $"$ & 26 & 87.5 \\
\hline 3 & " & 26 & 87.5 \\
\hline 5 & $"$ & 26 & 87.5 \\
\hline 1 & $\mathrm{mg} / \mathrm{ml} \mathrm{BaC}_{2} \mathrm{O}_{4}$ & 25 & 95 \\
\hline 2 & " $" 1$ & 25 & 90 \\
\hline 2.2 & $"$ & 25 & - \\
\hline 2.3 & $"$ & 25.3 & 88.5 \\
\hline 2.4 & " & 25.6 & - \\
\hline 2.5 & $\Rightarrow$ & 25.9 & 87.5 \\
\hline 3 & " & 25.9 & 87.5 \\
\hline 5 & $"$ & 25.9 & 87.5 \\
\hline
\end{tabular}

Acta Chem. Scand. 16 (1962) No. 5 
Influence of $\psi$ - and $\sigma$-factor concentrations on the plasma coagulation time. The $\psi$ - and $\sigma$-factors do not appear tc be indispensable factors for the coagulation of plasma, but both factors may be important for obtaining the maximal coagulation rate. Complete removal of $\varphi$-factor or $\sigma$-factor by adsorption results in a slight prolongation of the coagulation time of plasma. A detailed study of this effect (Table 4) revealed that 85-90\% of either of the two factors could be removed without effect on the coagulation time. The prolongation occurred simultaneously with the removal of the remaining $10-15 \%$ of either activity. An increase in the amounts of adsorbent up to $0.5 \%$ caused no further prolongation of the coagulation time. This means that the $x$-, $\delta$-, or $\varphi$-factors are not reduced below optimal concentrations by the quantities of adsorbent required for complete adsorption of $\psi$ - or $\sigma$-factors, and the prolongation of the coagulation time must be due to adsorption of the last 10$15 \%$ of the total $\psi$ - or $\sigma$-factor concentration. The accelerating effect of the two labile factors on the coagulation rate of fresh plasma may thus be considered optimal at about $12 \%$ of the normal level.

\section{DISCUSSION}

Stored plasma ${ }^{13-16}$ or plasma incubated under various conditions ${ }^{17,18}$ has regularly been used as a substitute for factor V-deficient plasma in assay of the factor $V$ activity of fresh plasma. The results obtained with artificial substrates are said to be comparable to those obtained with plasma from factor V-deficient patients. Factor $\mathrm{V}$ thus appears to be the only plasma factor, limiting thromboplastin coagulation rate, which drops below optimal levels during storage or incubation. In the methods referred to the results are read from standard dilution curves relating coagulation time to activity. A comparison of the results of different experiments seems to depend on a control of the potency of the accelerator solution (thromboplastin) and of the sensitivity of the substrate plasma.

In the proposed method for assay of labile chicken coagulation factors, standard dilution curves could not be used because of the observed differences between the dilution curves obtained with different stored chicken plasmas. The present method, therefore, can only be used for determination of the relative labile factor activities of plasmas tested simultaneously. On the other hand, with the use of identical substrates and identical accelerator solutions greater importance could be attributed to small, but reproducible differences in the activities of different plasmas, permitting detailed studies on the effects of adsorbents on the labile factor activity. The results obtained so far strongly suggest that the coagulation deficit in stored chicken plasma cannot be ascribed to a single coagulation factor, but rather to a number of plasma factors. These factors have in common the property of being reduced below optimal levels during short time storage. Their non-identity is inferred from the observed differences in behavior on adsorption of plasma with crystalline adsorbents. The present experiments have shown that the $x-, \delta$-, and $\varphi$ factors have no labile factor activity. The factors which determine the coagulation time of stored chicken plasma, therefore, belong to a different group of coagulation factors. The reduction in labile factor activity which occurs on 
adsorption of oxalated plasmas by strontium and barium carbonates is solely due to adsorption of two labile coagulation factors for which the terms $\psi$ factor and $\sigma$-factor have been adopted.

The adsorption curves suggest that some adsorbents have special adsorption sites ${ }^{12}$ for $\psi$-factor or $\sigma$-factor, whereas the two factors compete for the same adsorption sites on other adsorbents. The experiments indicate that these adsorption sites cannot be involved in the adsorption of $x$-, $\delta$-, or $\varphi$-factors.

The observed proportionality between adsorbed activity and amounts of adsorbent indicate that each adsorbent has a definite adsorption capacity for the adsorbable labile factor(s) which is independent of the plasma concentration of the factor(s). In analogy with what has been found for adsorption of $\varphi$ factor activity by calcium carbonate ${ }^{11,12}$, it seems probable that the minimum amount of adsorbent which gives maximal reduction of labile factor activity, i.e. complete adsorption of $\psi$-factor or $\sigma$-factor or both, will be proportional to the plasma concentration of the factor(s). Comparison of the concentrations of adsorbable labile factors of plasmas tested in different experiments may thus become possible. However, if inert material is adsorbed in competition with the labile factor(s), variations in the concentrations of such material will influence the results in much the same way as variations in the concentrations of the labile factor(s). Great variations in the levels of $x$-, $\delta$-, and $\varphi$-factors, which are adsorbed independently of the adsorption of the labile factors, have been shown not to affect the results of this kind of "adsorption titration".

\section{REFERENCES}

1. Nolf, P. Arch. Intern. Physiol. 6 (1908) 1.

2. Rhoads, J. E. and Panzer, L. M. J. Am. Med. Ass. 112 (1939) 309.

3. Quick, A. J. J. Am. Med. Ass. 114 (1940) 1342.

4. Quick, A. J. Am. J. Physiol. 140 (1943) 212.

5. Fantl, P. and Nance, M. H. Nature 158 (1946) 708.

6. Quick, A. J. Am. J. Physiol. 151 (1947) 63.

7. Ware, A. G., Guest, M. M. and Seegers, W. H. Science 106 (1947) 41.

8. Owren, P. A. Acta Med. Scand. Suppl. 194 (1947).

9. Nolf, P. Arch. Intern. Pharmacodyn. et Thérapie 70 (1945) 5.

10. Sørbye, Ø. and Kruse, I. Acta Chem. Scand. 14 (1960) 2177.

11. Sørbye, Ø. Acta Chem. Scand. 16 (1962) 799.

12. Sørbye, Ø. Acta Chem. Scand. 16 (1962) 903.

13. Quick, A. J. and Stefanini, M. J. Lab. Clin. Med. 33 (1948) 819.

14. Stefanini, M. Am. J. Clin. Pathol. 20 (1950) 233.

15. Lewis, M. L. and Ware, A. G. Proc. Soc. Exptl. Biol. Med. 84 (1953) 640.

16. Quick, A. J. J. Clin. Pathol. 13 (1960) 457.

17. Stormorken, H. Scand. J. Clin. Lab. Med. 9 (1957) 273.

18. Borchgrevink, C. F., Pool, J. G. and Stormorken, H. J. Lab. Clin. Med. 55 (1960) 625.

Received November 16, 1961.

Acta Chem. Scand. 16 (1962) No. 5 